\title{
Effects of Silica Fume on Water-resistant Property of Magnesium
}

\section{Oxychloride Cement}

\author{
Chen Wenhai ${ }^{1, a}$, Wu Chengyou ${ }^{1, b^{*}}$, Chen Fangyu ${ }^{1, c}$, Zheng Shuhai ${ }^{1, d}$ \\ ${ }^{1}$ School of Civil Engineering, Qinghai University Xi'Ning, China \\ achenwenhai304@163.com, ${ }^{\mathrm{b} w u c h e n g y o u 86 @ 163 . c o m}$, \\ c79828740@qq.com, ,540888538@qq.com
}

\begin{abstract}
Keywords: Magnesium oxychloride cement; silica fume; water-resistance property
Abstract: By incorporation of silica fume, magnesium oxychloride cement(MOC) with high water-resistance property can be formed. Here, the effects of silica fume on compressive strength, water-resistance property, hydration product and microstructure were investigated. X-ray diffraction and scanning electron microscopy were used to examine the hydration products of MOC. The experimental results indicated that by incorporating silica fume in the MOC, the water resistance improved, although the compressive strength decreased.
\end{abstract}

\section{Introduction}

Magnesium oxychloride cement (MOC), a type of air-dried magnesia-based cementing material [1], was formed by mixing magnesium oxide with concentrated solution of magnesium chloride. Compared with Portland cement, it has lots of advanced performance, such as high early strength, high bonding, quick setting and excellent fire resistance [2,3], and MOC is used extensively in residential and industry applications due to these superior properties. While, its poor water resistance has limited large engineering applications. Magnesium chloride cement is crystal network structure composed with $3 \mathrm{Mg}(\mathrm{OH})_{2} \cdot \mathrm{MgCl}_{2} \cdot 8 \mathrm{H}_{2} \mathrm{O}$ (abbreviated to Phase3)or $5 \mathrm{Mg}(\mathrm{OH})_{2} \cdot \mathrm{MgCl}_{2} \cdot 8 \mathrm{H}_{2} \mathrm{O}$ (abbreviated to Phase 5 ). Once water is added into the cement, chloride ions dissolve into water quickly which accelerates the solubility of crystal and Phase 5 or 3 with the network of closely packed fibrous crystals, has been severely damaged and transformed into loose, layered crystals of $\mathrm{Mg}(\mathrm{OH})_{2}$ that contain large pores[4]. Therefore, the water resistance became worse. Silica fume is one of the industrial wastes and being widely used into cement product. By adding silica fume into MOC cement, an energy saving and environmentally friendly cement material can be formed. The incorporation of silica fume can increase the compactness of cement and resist the erosion of water.

In this paper, silica fume was added into MOC and the influences of silica fume on MOC cement, including strength development, water resistance, phase composition as well as microstructure have been investigated.

\section{Experimental}

\section{Materials}

The magnesia used in this study is light-burnt magnesia (LBM) obtained by calcining magnesite at $750{ }^{\circ} \mathrm{C}$, and the chemical composition of the LBM is listed in Table 1. According to Dong's[5]report, the activity of $\mathrm{MgO}$ in this study is tested with the standardized hydration method. The result shows only $58.50 \%$ of active $\mathrm{MgO}$ consists in LBM. The magnesium chloride employed was hygroscopic hexahydrate crystal, $\mathrm{MgCl}_{2} \cdot 6 \mathrm{H}_{2} \mathrm{O}$, with a purity of $98 \%$ from Shandong Province. 
As well, silica fume is from Jiangsu province with the chemical composition listed in Table 1.

Table. 1 The chemical compositions of LBM and silica fume

\begin{tabular}{ccccccc}
\hline Compositions & $\mathrm{MgO}$ & $\mathrm{CaO}$ & $\mathrm{SiO}_{2}$ & $\mathrm{Fe}_{2} \mathrm{O}_{3}$ & $\mathrm{Al}_{2} \mathrm{O}_{3}$ & Others \\
\hline LBM & 80.20 & 1.30 & 6.07 & 0.41 & 0.15 & 11.87 \\
Silica fume & 1.50 & 0.50 & 92.0 & 2.00 & 1.00 & 3.00 \\
\hline
\end{tabular}

\section{Specimen preparation}

The molar ratio of active $\mathrm{MgO}$ to $\mathrm{MgCl}_{2}$ was 7 , and the water to cement ratio was fixed at 0.25 . For the preparation of MOC, LBM was firstly mixed with $\mathrm{MgCl}_{2} \cdot 6 \mathrm{H}_{2} \mathrm{O}$ and silica fume with different contents from $0-20 \%$, then a certain amount of water was added. After slowly agitating the mixture by hand for $60 \mathrm{~s}$, the paste was cast into $20 \mathrm{~mm} \times 20 \mathrm{~mm} \times 20 \mathrm{~mm}$ steel molds, sealed and cured at $20 \pm 3^{\circ} \mathrm{Cfor}$ about $24 \mathrm{~h}$ before demolding.

\section{Test method}

The reaction products in the neat MOC paste specimens were identified on an X-ray diffractometer (X-pert Pro) with copper $(\mathrm{Cu})$ target $(\mathrm{K} \alpha \mathrm{l}, \lambda=0 \cdot 15418 \mathrm{~nm})$, acceleration voltage of $30 \mathrm{kV}$, and $2 \theta$ range of $5 \sim 70^{\circ}$, and microstructure of the MOC pastes were characterized by scanning electron microscopy (SEM, JSM-5610LV)) on fractured surface with gold coating.

In this paper, the strength retention coefficient is defined as the ratio of the strength of the wet specimens after immersion in water to the strength of the dry specimens cured for 28 days before immersion in water. The larger the strength retention coefficients, the better the water resistance.

\section{Results and discussion}

\section{Effect of silica fume on compressive strength of MOC}

Figure 1 shows the effect of silica fume on the compressive strength of MOC paste. It can be seen that the compressive strength of MOC paste mixed with silica fume is reduced by the addition of silica fume. For example, the compressive strength of MOC paste cured at $28 \mathrm{~d}$ with $10 \%$ silica fume is only $73.4 \mathrm{MPa}$, which is $27.3 \%$ lower than that of $100.9 \mathrm{MPa}$ when mixed without silica fume. It can also be seen that the compressive strength of MOC increases with the silica fume contents increasing. When the content of silica fume is $20 \%$, the compressive strength of MOC specimen at the age of $28 \mathrm{~d}$ are $15 \%$ higher than that of specimens with $10 \%$ silica fume.

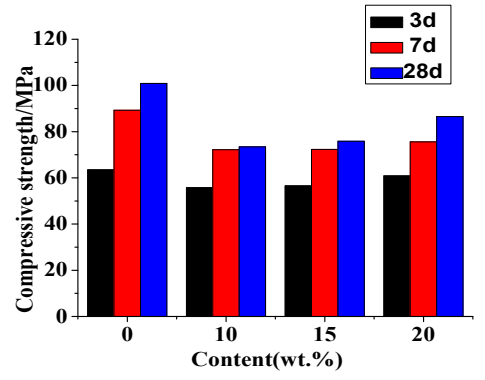

Fig.1 Effect of silica fume on the compressive strength of MOC paste

\section{Effect of silica fume on water-resistant property of MOC}

Figure 2 shows the effect of silica fume on water-resistant property of MOC, it can be seen that MOC with $20 \%$ silica fume has the best water-resistant property. Though soaked in water for 56 days, the strength retention coefficient remains 0.82 , which is much higher than others. While the water-resistant property of MOC with no silica fume was the worst, and the strength retention coefficient decreases sharply with the immersion time increasing. After adding silica fume, the water-resistance property of MOC has been improved obviously. 


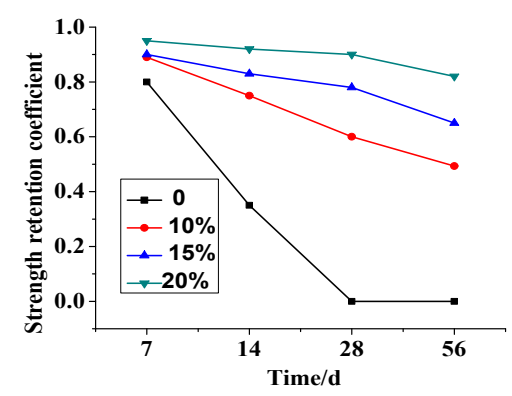

Fig.2 Effect of silica fume on water-resistant property of MOC

\section{Effect of silica fume on hydration product and microstructure}

Fig. 3 shows the XRD spectra of MOC before and after immersion in water. It can be seen that the main mineral phases present in MOC cured for 28 days before immersion in water is $5 \mathrm{Mg}(\mathrm{OH})_{2} \cdot \mathrm{MgCl}_{2} \cdot 8 \mathrm{H}_{2} \mathrm{O}$ and the diffraction peaks of Phase 5 become weak with the increase of silica fume, which indicates the incorporation of silica fume is adverse to the formation of Phase 5. This is because, with the addition of silica fume, the reactant is dispersed and isolated, so the concentration of reactant is diluted. Besides, the content of active $\mathrm{MgO}$ in the cement matrix decreases accordingly, which reduces the formation of Phase 5

After immersion in water, the diffraction peaks of $\mathrm{Mg}(\mathrm{OH})_{2}$ appears which indicates the crystals of Phase 5 have been severely damaged and transformed into loose crystals of $\mathrm{Mg}(\mathrm{OH})_{2}$. While, Phase 5 remain in MOC with silica fume. The high strength of MOC mainly depends on the interwoven and space filling properties of Phase 5, which can form a dense microstructure with minimum porosity [6]. Once Phase 5 disappears, the dense microstructure can be destroyed, and the compressive strength of MOC decreases sharply.

Fig 4 shows the images of MOC before and after immersion in water. As shown in Fig 4, MOC crystals cured for 28 days before immersion in water are needle shaped and crystals interlace and interweave together. Moreover, the crystals of MOC without silica fume are much longer and denser than that with $20 \%$ silica fume which confirms that the addition of silica fume is not benefit to the formation of Phase 5. After immersion in water for 56 days, the crystals of MOC without silica fume transform into plate-like $\mathrm{Mg}(\mathrm{OH})_{2}$, which is harmful to the strength of MOC paste. Whereas, the crystals of MOC with $20 \%$ silica fume remain in MOC paste and the microstructure is denser, which indicates that the addition of silica fume is benefit to the water-resistance property of MOC.

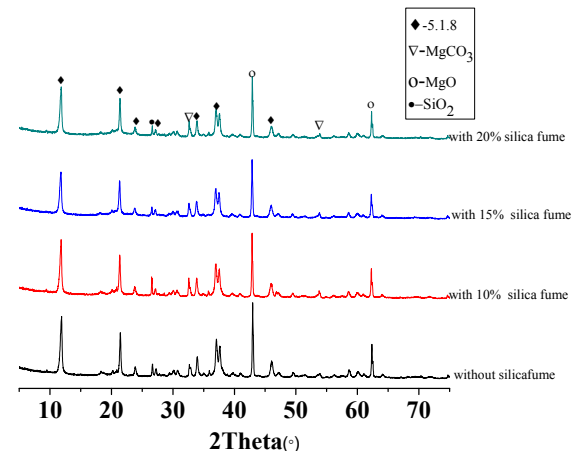

(a)

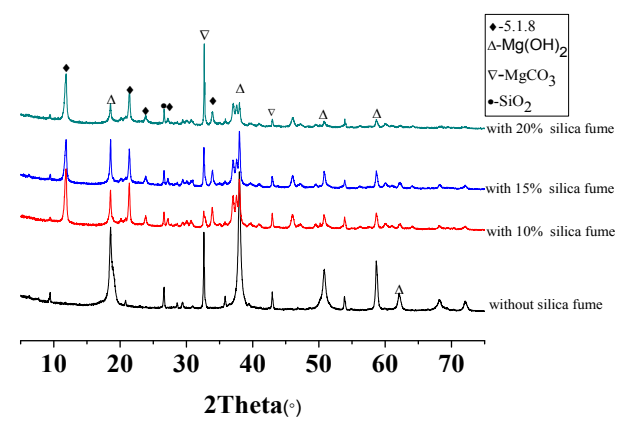

(b)

Fig. 3 XRD spectra of MOC paste before and after immersion in water(a)before(b)after 


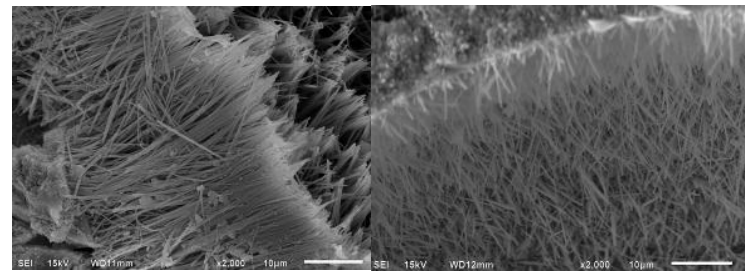

(a)

(b)

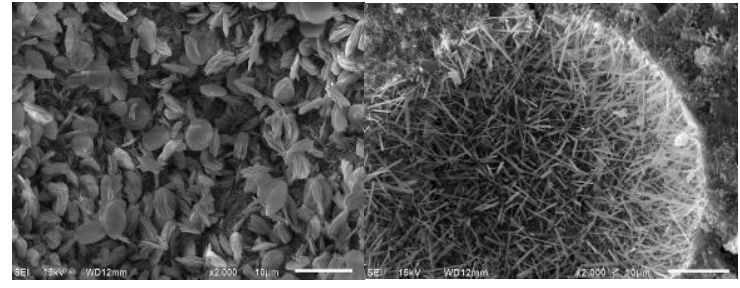

(c)

(d)

Fig.4 SEM images of MOC before and after immersion in water (a)MOC paste without silica fume before immersion in water(b)MOC paste with $20 \%$ silica fume before immersion in water(c) MOC

paste without silica fume after immersion in water(d) MOC paste with $20 \%$ silica fume after immersion in water

\section{Conclusions}

The influences of silica fume on the properties of MOC were investigated. By incorporating silica fume in the MOC, the water resistance improved, although the compressive strength decreased. The incorporation of silica fume is adverse to the formation of Phase 5.

\section{Acknowledgments}

This study was supported by the National Natural Science Foundations of China (grants No. 51662035, No. U1407104, No.51678304 and No. 21401209), Natural Science Foundations of Qinghai Province (grants No. 2015-ZJ-937Q and No. 2015-ZJ-722) and foundation teaching and research innovation team project of higher education institution of Qinghai province.

\section{References}

[1] Sorel S. On a new magnesium cement. C R Hebd Acad Sci 1867,65:102-106.

[2] Li Z, Chau CK. Influence of Molar Ratios on Properties of Magnesium Oxychloride Cement[J]. Cement Concrete Res., 2007, 37 (6): 866-870

[3] Chau CK, Li Z. Accelerated Reactivity Assessment of Light Burnt Magnesium Oxide[J]. J. Am. Ceram. Soc., 2008, 91 (5): 1 640-1 645

[4] Zhang C M, Deng D H. The stability of the reaction Products of magnesium oxychloride cement in water. Journal of Wuhan University of Technology, 1994, 9(3) :51.

[5] Dong JM, Yu HF, Zhang LM.(2010) Study on experimental conditions of hydration methods of determining active magnesium oxide content [J]. Salt Lake Res 18(1):38-41.

[6]Sglavo VM, Genua F , Conci A, et al. Influence of Curing Temperature on the Evolution of Magnesium Oxychloride Cement[J]. J. Mater. Sci., 2011, 46 (20): 6 726-6 733 